\section{Customized partially covered biodegradable stent for anastomotic leakage after esophago- jejunostomy}
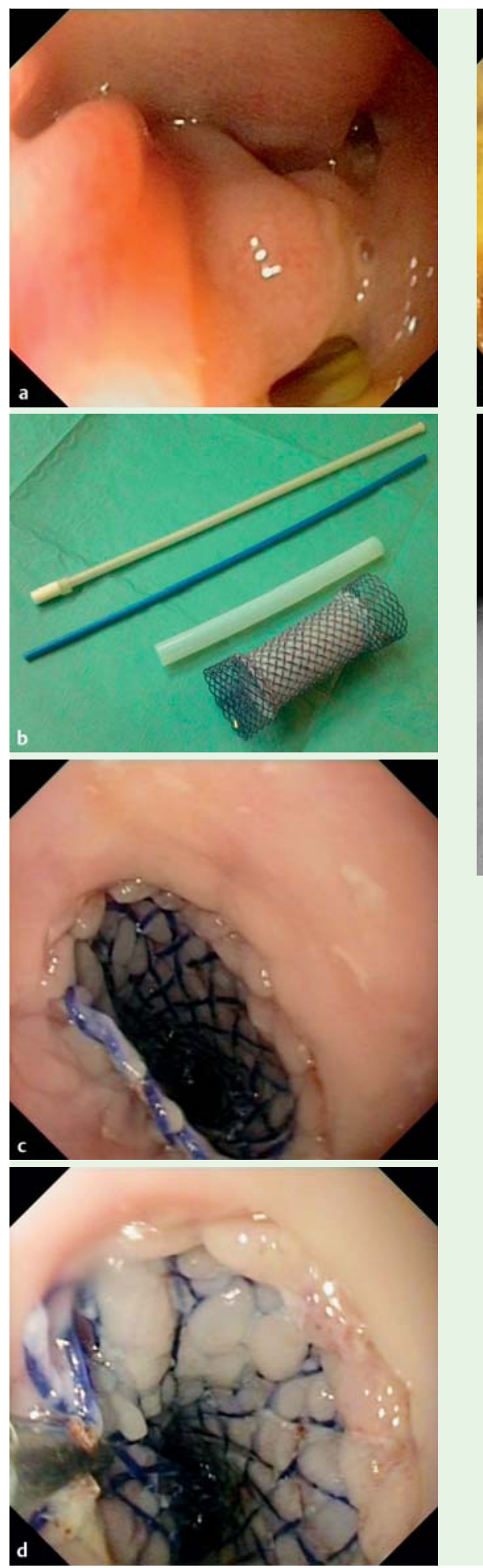
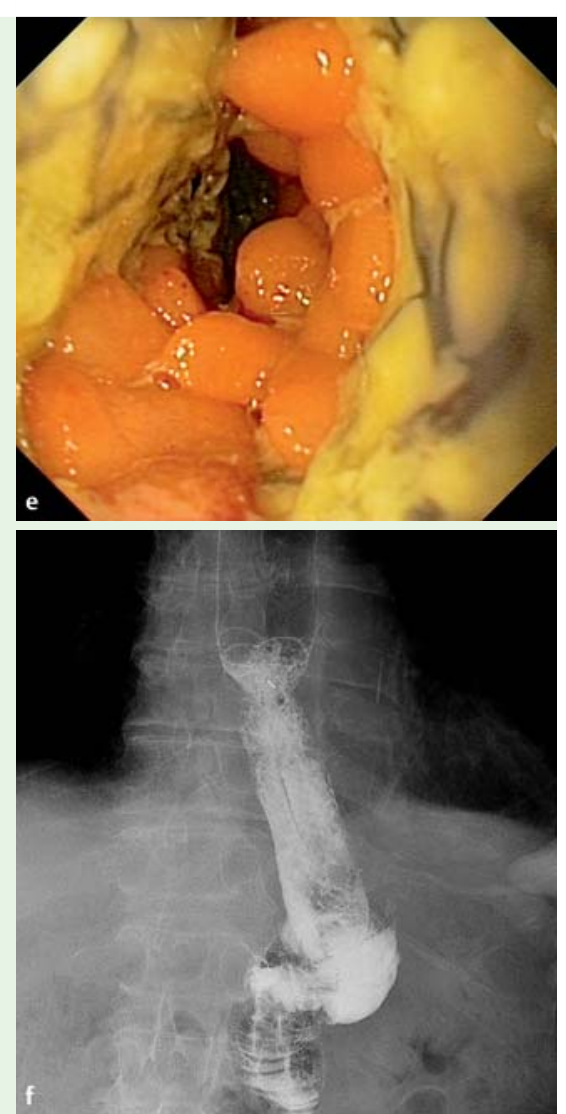

Fig. 1 a Postoperative endoscopic view of the esophagojejunal anastomosis leakage in a 73-year-old man who underwent a total gastrectomy plus splenectomy for a gastric adenocarcinoma. b The customized, partially covered biodegradable stent. c Proximal noncovered end of the stent at 4 days after placement. d Also at 4 days, an endoscopic clip (Resolution; Boston Scientific, Natick, Massachusetts, United States) was applied at the upper border of the stent, as an antimigration measure. e At 2 months after placement, the noncovered distal end of the stent was adhering well to the wall of the jejunum. $\mathbf{f}$ At 6 weeks after stent placement, barium transit showed nonleakage of the lumen with resolution of the dehiscence.
A 73-year-old man underwent a total gastrectomy plus splenectomy for a gastric adenocarcinoma (T3N1M0). At the early postoperative stage, the patient presented an esophagojejunostomy leak $(>1 \mathrm{~cm}$ diameter; Fig. 1 a). Medical management and endoscopic treatment were considered first. A customized, partially covered biodegradable stent ( $\bullet$ Fig. 1 b) (Ella Stent; ELLA-CS, Hradec Kralove, Czech Republic; diameter $31 / 25 / 31 \mathrm{~mm}$, length $110 \mathrm{~mm}$ ) was successfully placed under fluoroscopic and endoscopic guidance 5 weeks after surgery. At follow-up with endoscopic monitoring at 4 days ( $\bullet$ Fig. 1 c, d), 20 days, and 2 months ( $\bullet$ Fig. 1 e) after stent placement, adherence of each noncovered stent end (proximally and distally) was observed, as was an intrastent fold causing partial obstruction of the stent's lumen. Balloon dilation up to $20 \mathrm{~mm}$ was performed without incident, improving the luminal patency of the stent. The patient felt progressively better, and oral feeding was started after barium transit had shown nonleakage of the lumen with resolution of the dehiscence ( $\bullet$ Fig. $1 \mathrm{f}$ ). Upper endoscopy 14 weeks later confirmed the total disappearance of the biodegradable stent and sealing of the anastomotic leakage. A granular appearance of the mucosa was identified in the area where the noncovered stent ends had adhered ( Video 1 ). The patient had a favorable outcome and he is currently tolerating most kinds of food.

Anastomotic leakage of an esophagojejunal anastomosis after total gastrectomy is a severe complication associated with high mortality. In this situation, the use of self-expanding metal stents (SEMSs), fully or partially covered, has been reported to have a high stent-related adverse event rate $[1-3]$.

Partially covered biodegradable stents could overcome some of the problems encountered with SEMSs. Their main advantage over SEMSs is that endoscopic removal is not needed. But up to the present time, the only commercially available biodegradable stents are uncovered or fully covered [1 -5].

\section{Video 1}

Customized, partially covered biodegradable stent for anastomotic leakage after total gastrectomy. 


\section{Endoscopy_UCTN_Code_TTT_1AO_2AI}

\section{Competing interests: None}

\section{Joan B. Gornals ${ }^{1}$, Laura Rivas ${ }^{1}$, Humberto Aranda², Monica Miro², Maica Galan ${ }^{3}$}

${ }^{1}$ Endoscopy Unit, Department of Digestive Diseases, Hospital Universitari de Bellvitge-IDIBELL, Barcelona, Spain

2 Department of Surgery, Hospital Universitari de Bellvitge-IDIBELL, Barcelona, Spain

${ }^{3}$ Department of Medical Oncology, Institut Català d'Oncologia DiR-IDIBELL, Barcelona, Spain

\section{References}

1 Černá M, Köcher M, Válek Vet al. Covered biodegradable stent: new therapeutic option for the management of esophageal perforation or anastomotic leak. Cardiovasc Intervent Radiol 2011; 34: 1267-1271

2 van Boeckel PG, Dua KS, Weusten BL et al. Fully covered self-expandable metal stents (SEMS), partially covered SEMS and self-expandable plastic stents for the treatment of benign esophageal ruptures and anastomotic leaks. BMC Gastroenterol 2012; 12: 19

3 Hoeppner J, Kulemann B, Seifert $G$ et al. Covered self-expanding stent treatment for anastomotic leakage: outcomes in esophagogastric and esophagojejunal anastomoses. Surg Endosc 2014; 28: 1703 -1711

4 van Boeckel PG, Vleggaar FP, Siersema PD. Biodegradable stent placement in the esophagus. Expert Rev Med Devices 2013; 10: $37-43$

5 Repici A, Vleggaar FP, Hassan C et al. Efficacy and safety of biodegradable stents for refractory benign esophageal strictures: the BEST (Biodegradable Esophageal Stent) study. Gastrointest Endosc 2010; 72: 927 934
Bibliography

Dol http://dx.doi.org/

10.1055/s-0034-1390864

Endoscopy 2015; 47: E137-E138

(c) Georg Thieme Verlag KG

Stuttgart · New York

ISSN 0013-726X

\section{Corresponding author}

Joan B. Gornals, MD, PhD

Endoscopy Unit

Department of Digestive Diseases

Hospital Universitari de Bellvitge-IDIBELL

Feixa Llarga $\mathrm{s} / \mathrm{n}$

08907 L'Hospitalet de Llobregat

Barcelona

Spain

Fax: +34-93-2607681

jgornals@bellvitgehospital.cat 